\title{
Soft-switching SiC interleaved boost converter
}

DOI:

10.1109/APEC.2015.7104462

Link to publication record in Manchester Research Explorer

\section{Citation for published version (APA):}

Ahmed, M. R., Calderon-Lopez, G., Bryan, F., Todd, R., \& Forsyth, A. J. (2015). Soft-switching SiC interleaved boost converter. In Applied Power Electronics Conference and Exposition (APEC), 2015 IEEE (pp. 941-947). IEEE. https://doi.org/10.1109/APEC.2015.7104462

\section{Published in:}

Applied Power Electronics Conference and Exposition (APEC), 2015 IEEE

\section{Citing this paper}

Please note that where the full-text provided on Manchester Research Explorer is the Author Accepted Manuscript or Proof version this may differ from the final Published version. If citing, it is advised that you check and use the publisher's definitive version.

\section{General rights}

Copyright and moral rights for the publications made accessible in the Research Explorer are retained by the authors and/or other copyright owners and it is a condition of accessing publications that users recognise and abide by the legal requirements associated with these rights.

\section{Takedown policy}

If you believe that this document breaches copyright please refer to the University of Manchester's Takedown Procedures [http://man.ac.uk/04Y6Bo] or contact uml.scholarlycommunications@manchester.ac.uk providing relevant details, so we can investigate your claim.

\section{OPEN ACCESS}


This paper was published at the IEEE Applied Power Electronics Conference and Exposition (APEC) in Mar. 2015, doi 10.1109/APEC.2015.7104462, and is available at:

http://ieeexplore.ieee.org/stamp/stamp.jsp?tp=\&arnumber=7104462

M. R. Ahmed, G. Calderon-Lopez, F. Bryan, R. Todd and A. J. Forsyth, " SoftSwitching SiC Interleaved Boost Converter," IEEE Applied Power Electronics Conference and Exposition (APEC), pp. 941-947, 15-19 Mar. 2015, doi: 10.1109/APEC.2015.7104462.

(C) 2015 IEEE. Personal use of this material is permitted. Permission from the IEEE must be obtained for all other uses, in any current or future media, including reprinting/republishing this material for advertising or promotional purposes, creating new collective works, for resale or redistribution to servers or lists, or reuse of any copyrighted component of this work in other works. 


\title{
Soft-Switching SiC Interleaved Boost Converter
}

\author{
M. R. Ahmed, G. Calderon-Lopez, F. Bryan, R. Todd and A. J. Forsyth \\ School of Electrical and Electronic Engineering, Power Conversion Group \\ The University of Manchester \\ Manchester, U.K. \\ md.rishad.ahmed@postgrad.manchester.ac.uk
}

\begin{abstract}
A DC-DC converter topology is presented combining the soft switching effects of the Snubber Assisted Zero Voltage and Zero Current Transition (SAZZ) topology and the increased inductor frequency of the dual interleaved boost converter with interphase transformer. The snubber capacitors and output capacitances of the main devices are discharged prior to turn on using a single auxiliary inductor, eliminating turn on losses. Furthermore, the turn off losses are significantly reduced since the energy stored in the device output capacitance at turn off is recovered at turn on. The effectiveness of the topology is demonstrated on a $\mathrm{SiC}$ prototype operating at $12.5 \mathrm{~kW}, 112 \mathrm{kHz}$, reducing the switching losses by $50 \%$.
\end{abstract}

Keywords- Dual Interleaved Boost, Soft Switching, SiC MOSFET

\section{INTRODUCTION}

Future DC-DC converters for transport applications are required to have an increased power density, with current targets in the region of $30 \mathrm{~kW} / 1$ [1]. This is particularly relevant for automotive and aerospace applications where the power levels are currently several tens of kilowatts and increasing.

Recently the availability of high power SiC power devices has allowed the operating frequency of hard-switched high power, $600 \mathrm{~V} \mathrm{DC}$-DC converters to be increased up to $75 \mathrm{kHz}$ $[2,3]$. This allows the bulky passive components to be reduced in size. However, even with power switching devices using new technologies, $\mathrm{SiC}$ and $\mathrm{GaN}$ for example, switching losses still limit the practical frequency of higher power converters.

At lower frequencies using $\mathrm{Si}$ technologies, snubber assisted circuits have been used to increase the frequency of traditional converters to reduce the converter size and improve efficiency [4-7]. Snubber Assisted Zero Voltage and Zero Current Transition (SAZZ) single and multiphase phase Si and $\mathrm{SiC}$ boost converters have been reported in the last decade [811] with frequencies above $100 \mathrm{kHz}$ and with efficiencies around $98 \%$.

The impact of the increased switching speeds of $\mathrm{SiC}$ power devices in hard switched motor drives has been studied in [12], and it has been suggested that exploiting the full switching speed capacity of the $\mathrm{SiC}$ devices increases the EMI generation and affects the reliability of inverter-fed electrical machines. A maximum $d v / d t$ of $6 \mathrm{kV} / \mu \mathrm{s}$ is recommended for $600-\mathrm{V}$ inverters [12]; therefore, methods to limit the $d v / d t$ to comparable levels in SiC DC-DC converters may be desirable, and soft-switching techniques such as the one presented in this

The authors thank the UK Engineering and Physical Sciences Research Council (EPSRC) for the funding of this project as part of the Centre for Power Electronics. paper offer a good solution.

This research proposes the use of an auxiliary switching circuit in a $\mathrm{SiC}$ interleaved boost converter to reduce losses, limit the maximum $d v / d t$ and allow an increase in operating frequency. The turn on switching losses in the main devices are completely eliminated and the turn off losses are significantly reduced since the energy stored in the device output capacitance at turn off is recovered at turn on. The turn off losses could be further reduced by the use of additional snubber capacitors. The practical results show that the losses in the auxiliary circuit are much lower than the saving in switching losses.

\section{CIRCUIT DESCRIPTION AND OPERATION}

The converter topology is based on that of the dual interleaved boost converter with interphase transformer [2, 1315] and benefits input and output ripple currents that are at twice the switching device frequency. The topology is shown in Fig. 1 where an auxiliary switch and diode are added to each switching leg, along with snubber capacitors, $\mathrm{C}_{\mathrm{S} 1}$ and $\mathrm{C}_{\mathrm{S} 2}$, in parallel with the main switching devices $Q_{1}-Q_{4}$. The snubber capacitors may be partly or entirely formed by the output capacitance of the main devices, $\mathrm{Q}_{1}-\mathrm{Q}_{4}$. The simple auxiliary circuits utilize a single small inductor, $\mathrm{L}_{1}$, connected to the input which forms part of the total input inductance. By turning on the auxiliary device immediately before the main switch, ZVZCS turn on of the main switch can be achieved along with zero current (ZCS) turn on of the auxiliary device. Both devices are ideally turned off simultaneously with ZVS and ZCS for the main switch and auxiliary device respectively. This topology offers the soft switching benefits of the SAZZ converter topology but with a reduced number of devices per leg. There is a single input auxiliary inductor operating at twice the switching frequency and the potential exists for integrating the main and auxiliary inductors.

The circuit in Fig. 1 is shown in bi-directional form with main transistors $\mathrm{Q}_{1}-\mathrm{Q}_{4}$, however, the analysis presented in this paper only considers step-up operation and duty ratios, D, above 0.5 . It is possible to achieve soft switching during the reverse buck mode, but this requires replacing the auxiliary diodes $\left(\mathrm{D}_{\mathrm{AUX} 1}\right.$ and $\left.\mathrm{D}_{\mathrm{AUX} 2}\right)$ with MOSFETs to form a back-toback configuration with the existing auxiliary switches $\left(\mathrm{Q} 1_{\mathrm{A}}\right.$ and $\mathrm{Q} 2{ }_{\mathrm{A}}$, respectively) [16]. The SAZZ topology has inherent restrictions to achieve ZVS at turn on for duty ratios below 0.5 ; however, this can be overcome by operating the upper main 


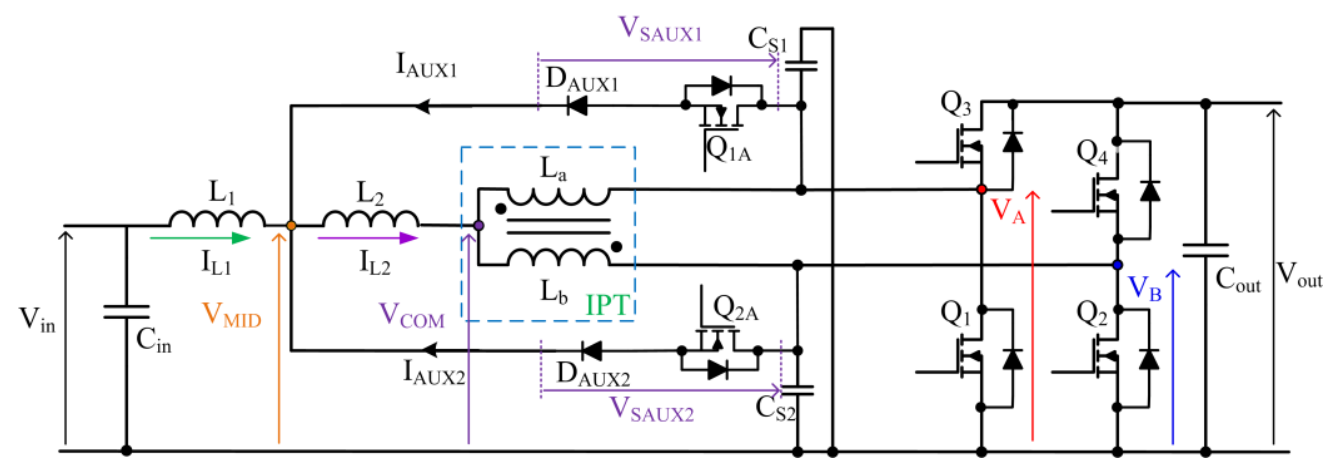

Fig. 1. Circuit schematic.

switches, $\mathrm{Q}_{3}$ and $\mathrm{Q}_{4}$, in a synchronous rectification mode as shown in [16].

\section{CIRCUIT ANALYSIS AND DESIGN}

To explain the operation of the converter, Fig. 2 shows the main current and voltage waveforms during one half of the switching period when the duty ratio is greater than 0.5 . The waveforms show the gate voltages of the main and auxiliary switches, VG_Q1, VG_Q2, VG_Q1 1 and VG_Q2 ${ }_{\mathrm{A}}$; the voltages at the mid points of the switching legs, $V_{A}$ and $V_{B}$, the currents flowing in the anti-parallel diodes of the top devices, $\mathrm{I}_{\mathrm{D} 3}$ and $\mathrm{I}_{\mathrm{D} 4}$, the inductor currents $\mathrm{I}_{\mathrm{L} 1}$ and $\mathrm{I}_{\mathrm{L} 2}$, the voltage at the connection of $\mathrm{L}_{1}$ and $\mathrm{L}_{2}, \mathrm{~V}_{\mathrm{MID}}$, the currents flowing in the snubber capacitances and auxiliary switches, $\mathrm{I}_{\mathrm{CS} 1}, \mathrm{I}_{\mathrm{CS} 2}, \mathrm{I}_{\mathrm{AUX} 1}$ \& $\mathrm{I}_{\mathrm{AUX} 2}$, the voltages across the auxiliary MOSFET-diode pairs, $\mathrm{V}_{\mathrm{SAUX} 1}$ and $\mathrm{V}_{\mathrm{SAUX} 2}$, the currents in the IPT windings and the main switches, $\mathrm{I}_{\mathrm{La}}, \mathrm{I}_{\mathrm{Lb}}, \mathrm{I}_{\mathrm{Q} 1}$ and $\mathrm{I}_{\mathrm{Q} 2}$; and finally, the voltages across the main and auxiliary inductors, $\mathrm{V}_{\mathrm{L} 2}$ and $\mathrm{V}_{\mathrm{L} 1}$. Fig. 3 identifies the main sub-circuits occurring during the seven individual sub-periods depicted in Fig. 2. The circuit is symmetrical in operation with the main leg devices, $\mathrm{Q}_{1}$ and $\mathrm{Q}_{2}$ operating with half a cycle delay. The currents flowing in the two halves of the IPT are assumed to be equal on the condition that their inductances are high, compared to those of $\mathrm{L}_{1}$ and $\mathrm{L}_{2}$.

\section{A. Sub-period $T_{I}$}

Before this interval, transistor $\mathrm{Q}_{1}$ and its opposite diode, $\mathrm{D}_{4}$ are conducting. At time $t_{0}$, the auxiliary switch $\mathrm{Q}_{2 \mathrm{~A}}$ is turned on. The rate of change of current is restricted by inductor $\mathrm{L}_{1}$. The current in $\mathrm{L}_{1}$ decreases, whilst the current in $\mathrm{L}_{2}$ increases, increasing the current in $\mathrm{L}_{\mathrm{a}}, \mathrm{L}_{\mathrm{b}}$ and the conducting switch $\mathrm{Q}_{1}$. As the current in $\mathrm{Q}_{2 \mathrm{~A}}$ increases, the current in the anti-parallel diode $\mathrm{D}_{4}$ decreases until it reaches zero, at time $\mathrm{t}_{1}$.

\section{B. Sub-period $T_{2}$}

When diode $\mathrm{D}_{4}$ stops conducting snubber capacitor $\mathrm{C}_{\mathrm{s} 2}$ begins discharging through $\mathrm{Q}_{2 \mathrm{~A}}, \mathrm{D}_{\mathrm{AUX} 2 \mathrm{~A}}$, and $\mathrm{L}_{1}$ in a resonant manner.

The auxiliary switch and diode carry both the discharge current of the capacitor and the current through $\mathrm{L}_{b}$ which continues to flow. This current and the capacitor discharge current reach a peak at time $t_{2}$.

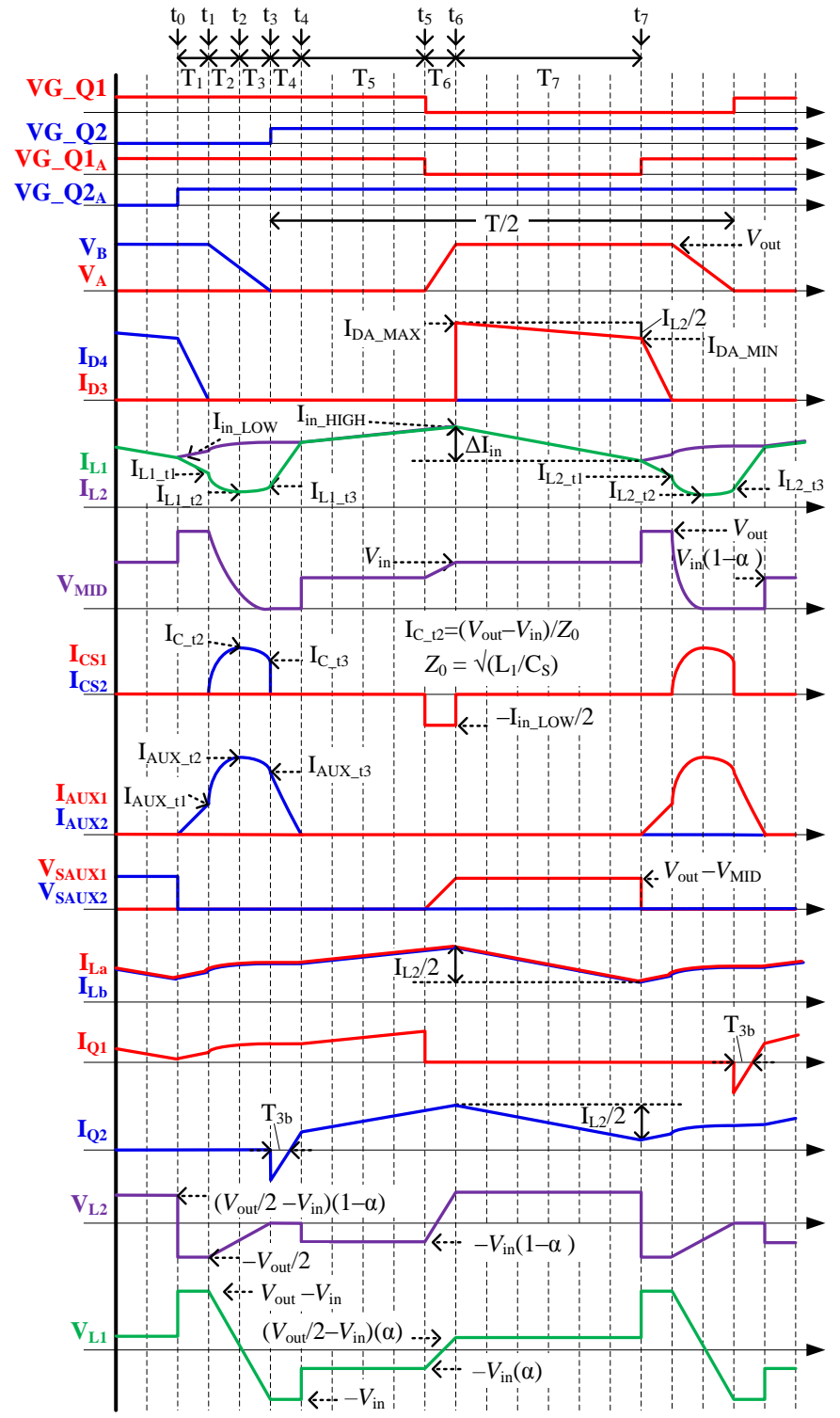

Fig. 2. Ideal operating waveforms for D>0.5. $\alpha=L_{1} /\left(L_{1}+L_{2}\right)$. 

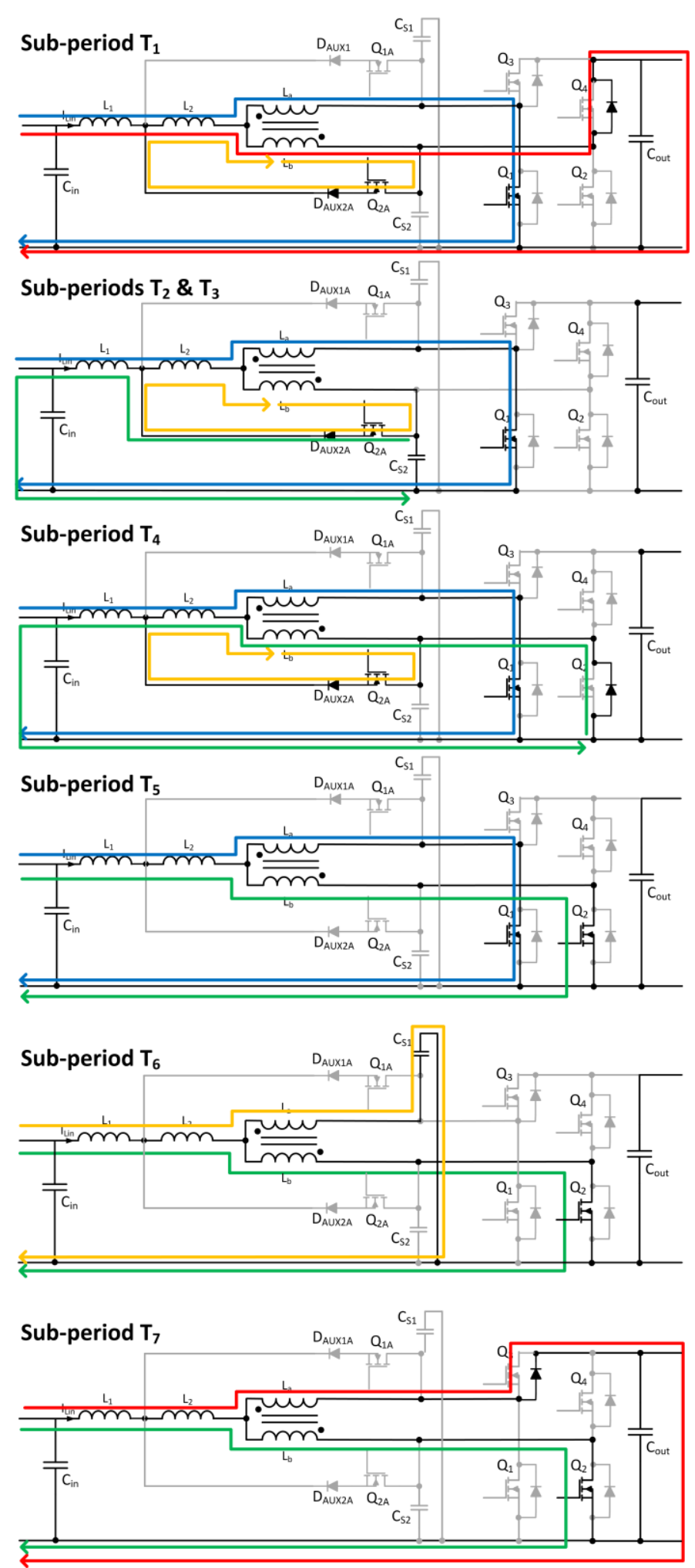

Fig. 3. Sub-circuits during the intervals of a switching period, $\mathrm{D}>0.5$.

\section{Sub-period $T_{3}$}

The capacitor current begins to decrease after $t_{2}$, and at time $\mathrm{t}_{3}$ the capacitor voltage reaches zero. By / after this time, the switch $\mathrm{Q}_{2}$ can be turned on with zero voltage switching.

\section{Sub-period $T_{4}$}

The snubber capacitor current transfers to antiparallel diode $\mathrm{D}_{2}$. Current, $\mathrm{I}_{\mathrm{L} 1}$ rises and auxiliary current, $\mathrm{I}_{\mathrm{AUX} 2}$ falls to zero. At time $t_{4}$, the currents of $L_{1}$ and $L_{2}$ are equal.

\section{E. Sub-period $T_{5}$}

$\mathrm{V}_{\mathrm{COM}}$ is zero and $\mathrm{V}_{\text {in }}$ is applied across the series connected input inductors. The inductor current rises until time $t_{6}$, when $\mathrm{Q}_{1}$ and $\mathrm{Q}_{1 \mathrm{~A}}$ are turned off.

\section{F. Sub-period $T_{6}$}

$\mathrm{Q}_{1}$ is turned off and snubber capacitor $\mathrm{C}_{\mathrm{S} 1}$ is charged providing zero voltage turn off of $\mathrm{Q}_{1}$. When $\mathrm{C}_{\mathrm{S} 1}$ is charged, the current transfers to $\mathrm{D}_{3}$.

\section{G. Sub-period $T_{7}$}

Transistor $\mathrm{Q}_{2}$ and its opposite diode, $\mathrm{D}_{3}$ conduct. As the operation is symmetrical, then the sub-intervals for the second phase are a mirror image of those describe above for the first phase to complete a switching period.

\section{DESIGN EQUATIONS}

The advance time for the turn on of the auxiliary devices relative to the turn-on of the main switch is the sum of the intervals $T_{1}$ to $T_{3}$, where:

$$
\begin{gathered}
T_{1}=\frac{L_{1} I_{\text {in_LOW }}}{2\left(V_{\text {out }}-V_{\text {in }}\right)} \\
T_{2}=\frac{\pi \sqrt{L_{1} C_{S}}}{2} \\
T_{3}=\frac{\cos ^{-1}\left[\frac{V_{\text {in }}}{\left(V_{\text {in }}-V_{\text {out }}\right)}\right]-\frac{\pi}{2}}{\omega_{0}}
\end{gathered}
$$

and the parameters of the resonant circuit are,

$$
\begin{gathered}
Z_{0}=\sqrt{\frac{L_{1}}{C_{S}}} \\
\omega_{0}=\frac{1}{\sqrt{L_{1} C_{S}}}
\end{gathered}
$$

The peak current in the snubber capacitor occurs at time $t_{2}$, and its value is

$$
I_{C S_{-} t 2}=\frac{V_{\text {out }}-V_{\text {in }}}{Z_{0}}
$$



$\mathrm{t}_{2}$ is

Whilst the peak current in the auxiliary switch and diode at

$$
I_{A U X_{-} t 2}=\frac{I_{i n_{-} L O W}}{2}+I_{C S_{-} t 2}
$$

The voltage rating of the auxiliary switch is lower than that of the main leg switches,

$$
V_{Q A U X}=V_{\text {out }}-V_{\text {in }}
$$

\section{PRACTICAL IMPLEMENTATION-ADVANCE TIME}

Turning on the main switches at the exact instants where the voltage across the snubber capacitor reaches zero, $t_{3}$, would be impractical and difficult to achieve due to the time scales involved in the transients, time delays in logic and gate driver circuitry and unnecessary added complexity to the controller. The best solution to keep a simple control and achieve soft switching is to turn on the auxiliary switches by a fixed period before the main switches.

The advance time should ensure that the snubber capacitor is fully-discharged to avoid turn-on losses; however, when the turn-on transient of the main switch is delayed after $t_{3}$ there is a period, $\mathrm{T}_{3 \mathrm{~b}}$, where the devices can be turned on to achieve the ZVS, as depicted in the transistor current waveforms $\mathrm{I}_{\mathrm{Q} 1}$ and $\mathrm{I}_{\mathrm{Q} 2}$ in Fig. 2.

During the sub-period $\mathrm{T}_{3 \mathrm{~b}}$, the snubber capacitor remains discharged until the current in the auxiliary circuit reaches zero. If the main switch is not turned on in the interval of $\mathrm{T}_{3 \mathrm{~b}}$, then the capacitor will recharge.

The time $\mathrm{T}_{3 \mathrm{~b}}$ is given by (9),

$$
T_{3 b}=L_{1} \frac{I_{C S_{-} t 3}}{V_{\text {in }}}
$$

where,

$$
I_{C S_{-} t 3}=I_{C S_{-} t 2} \sin \left(\omega_{0}\left(T_{2}+T_{3}\right)\right) \text {. }
$$

$\mathrm{T}_{3 \mathrm{~b}}$ is therefore dependent only on the input voltage, output voltage and the sizes of $\mathrm{L}_{1}$ and the snubber capacitor. These parameters are not load-dependent when operating the continuous conduction mode and therefore they can be predefined during converter design.

\section{PROTOTYPE DESCRIPTION}

A $12.5 \mathrm{~kW}$ forced air cooled demonstrator has been constructed to boost the input voltage from $100 \mathrm{~V}$ to $400 \mathrm{~V}$.

The main converter leg devices are CREE half-bridge CAS100H12AM1 SiC modules. Each auxiliary circuit is formed by a CREE diode, C4D40120D, and a SiC MOSFET, C2M0080120D.
The $1 \mathrm{nF}$ output capacitance of the CREE modules is used to form the snubber capacitors [17]. The inductors $L_{1}$ and $L_{2}$ are foil wound ferrites, with values of $1 \mu \mathrm{H}$ and $12 \mu \mathrm{H}$, respectively. The interphase transformer is also ferrite core based with a stranded enamelled wire winding. The differential inductance was of $0.8 \mathrm{mH}$.

The converter peak current mode control is implemented using an UCC28220 PWM controller, the main switch PWM signals are delayed at turn on by a fixed delay determined by an analogue delay circuit.

Both gate drivers for the $\mathrm{SiC}$ module and the auxiliary $\mathrm{SiC}$ MOSFET used Murata MGJ2D152005SC isolated $2 \mathrm{~W}$ dual output DC-DC converters for generating $20 \mathrm{~V} /-5 \mathrm{~V}$ gate pulses. TEXAS INSTRUMENTS high speed gate driver UCC27531 was used in series with ZETEX high speed gate drivers (ZXGD3004E6) for driving each MOSFET.

Fig. 4 shows the CAD drawing of the converter and Fig. 5 shows the total experimental setup. The next section will discuss the simulation and experimental results.

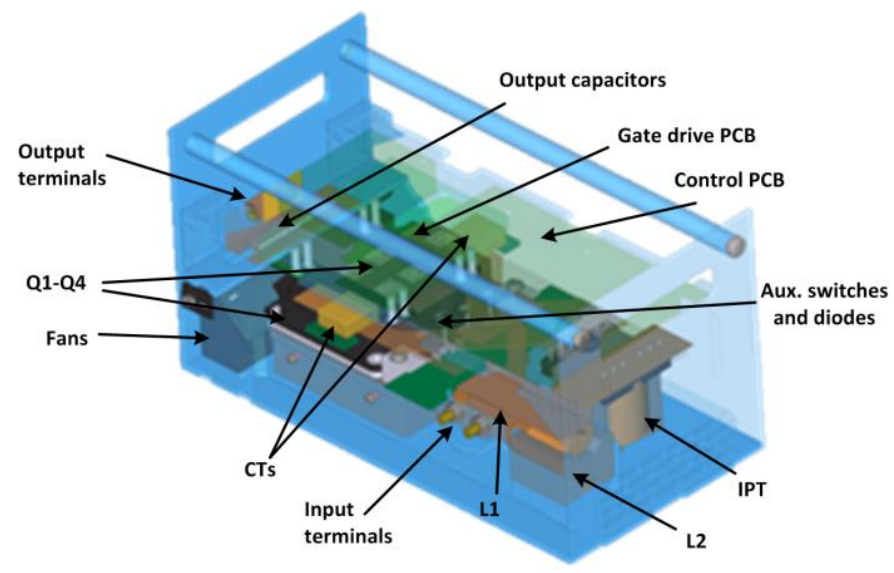

Fig. 4. Topology demonstrator and CAD drawing.

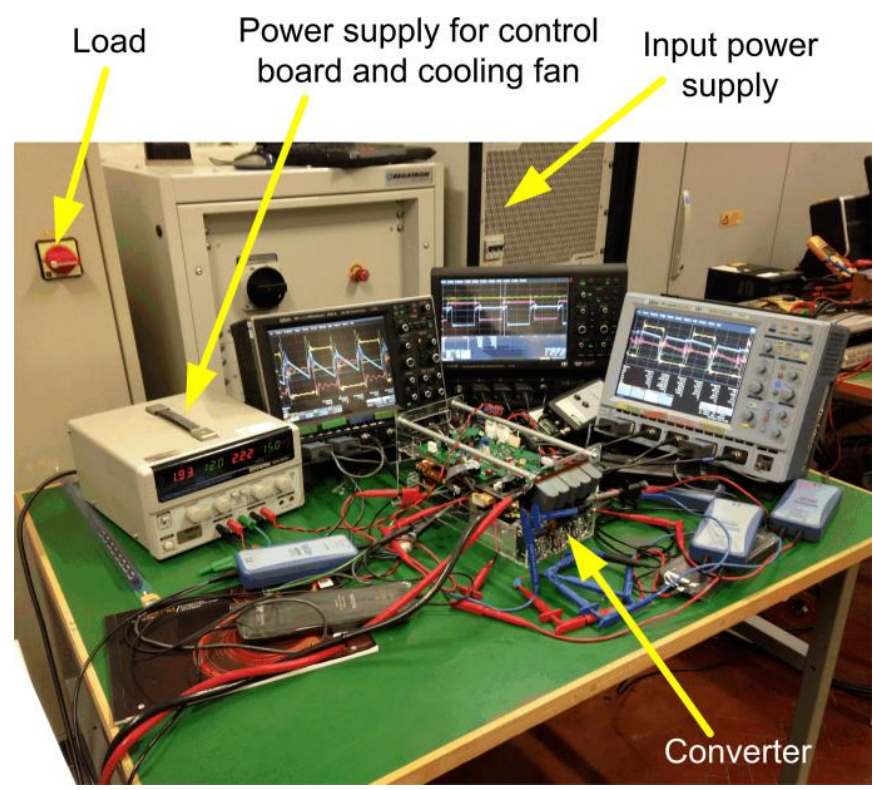

Fig. 5. Experimental set-up. 


\section{PROTOTYPE RESULTS ANALYSIS}

\section{A. Simulation Results}

The prototype demonstrator was simulated in LTspice IV using the SPICE models of the SiC MOSFETs and SiC Schottky diodes provided by CREE. The simulated waveforms (Fig. 6) match closely with the theoretical predictions discussed in Section III. The results are shown for $174 \mathrm{~V}$ to $410 \mathrm{~V}, 112$ $\mathrm{kHz}$ operation $(12.9 \mathrm{~kW})$ for comparison with the experimental results. A delay of $0.4 \mu \mathrm{s}$ between the auxiliary and main device turn on instants was required to achieve ZVZCS during the turn on of the main switching devices, $\mathrm{Q}_{1}$ and $\mathrm{Q}_{2}$. The high frequency ringing in the auxiliary branch current is due to the resonance between the stray inductance included in the device models and output capacitance of the auxiliary switch. The efficiency of the converter was around $98.7 \%$ from the simulation.

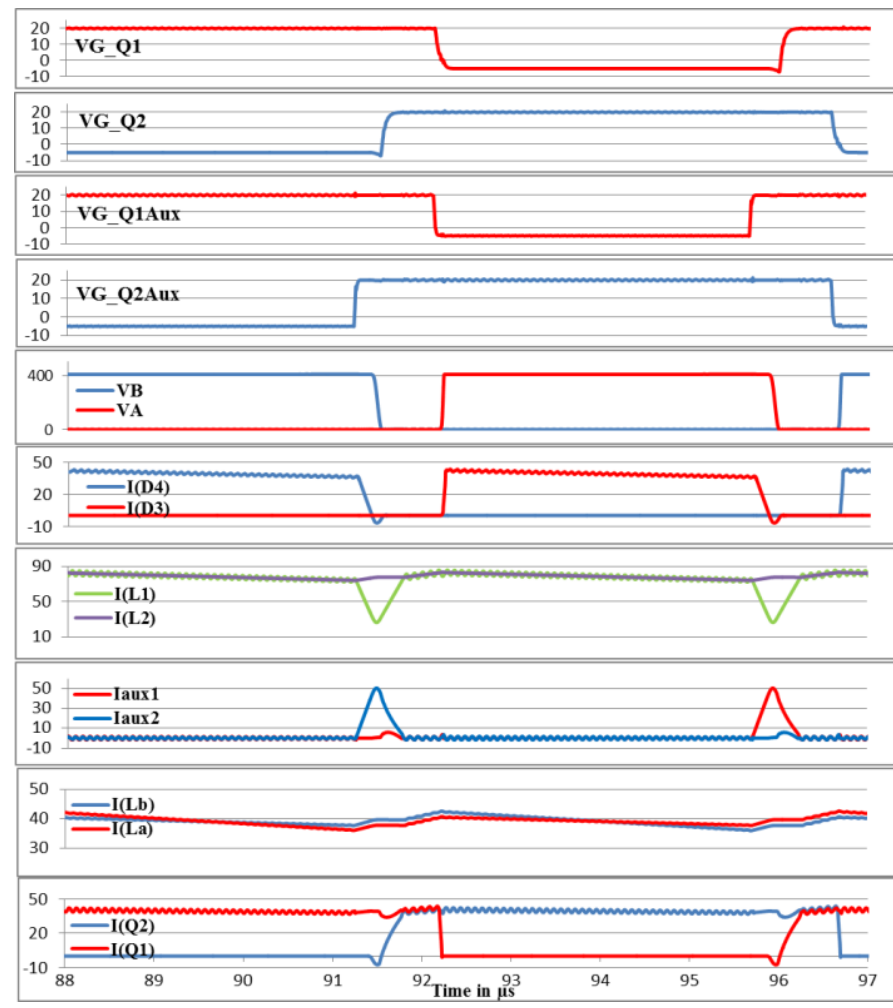

Fig. 6. Simulation results $\left(\mathrm{V}_{\text {in }}=174 \mathrm{~V}, \mathrm{~V}_{\text {out }}=410 \mathrm{~V}, \mathrm{I}_{\text {inavg }}=74.1 \mathrm{~A}, \mathrm{I}_{0}=31 \mathrm{~A}\right.$, $\mathrm{P}_{\mathrm{in}}=12.9 \mathrm{~kW}, \eta=98.7 \%$ )

\section{B. Experimental Results}

The experimental verification of the $\mathrm{SiC}$ based prototype was done for $174 \mathrm{~V}$ to $400 \mathrm{~V}, 112 \mathrm{kHz}$ and $12.6 \mathrm{~kW}$ operation. Fig. 7 shows experimental results from the prototype converter. The auxiliary inductor current, $\mathrm{I}_{\mathrm{L} 1}$, the main inductor current, $\mathrm{I}_{\mathrm{L} 2}$, and one of the IPT branch currents, $\mathrm{I}_{\mathrm{Lb}}$ are shown in Fig. 7(a). These currents match well with the theory and simulation. Fig. 7(b) and 7(c) show the ZVZCS at turn on for both of the main switches, $Q_{1}$ and $Q_{2}$, by showing their respective auxiliary resonance branch currents, drain to source voltages and gate to source voltages. The time delay between the auxiliary and main switch gate pulses was $0.45 \mu \mathrm{s}$ to achieve the ZVZCS turn on, which is quite close to the total

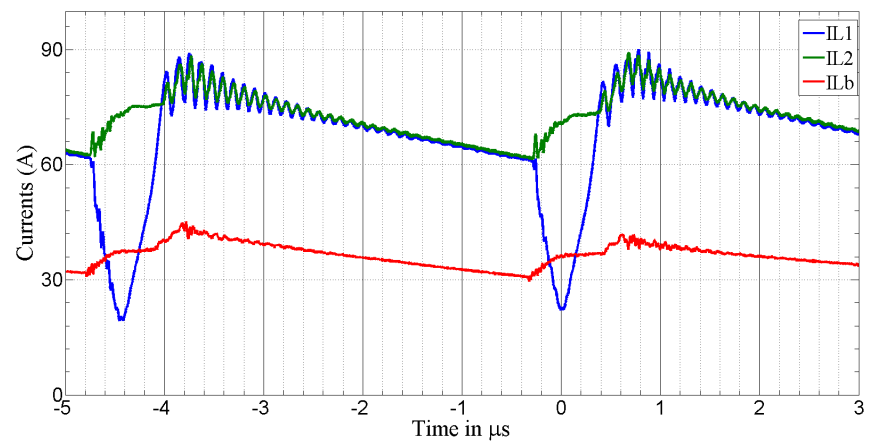

(a)

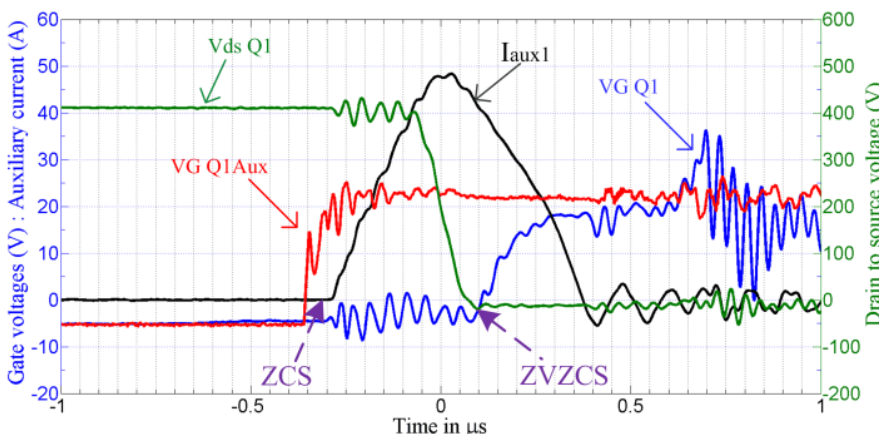

(b)

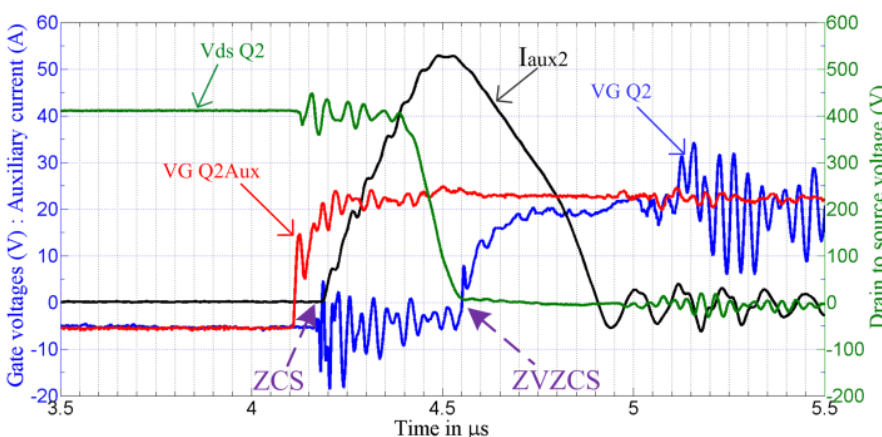

(c)

Fig. 7. Experimental results: (a) Inductor and IPT currents, (b) and (c) ZVZCS turn on transients $\left(\mathrm{V}_{\text {in }}=174 \mathrm{~V}, \mathrm{~V}_{\text {out }}=400.6 \mathrm{~V}, \mathrm{I}_{\text {inavg }}=72.3 \mathrm{~A}, \mathrm{I}_{\mathrm{o}}=\right.$ $30.8 \mathrm{~A}, \mathrm{P}_{\mathrm{in}}=12.6 \mathrm{~kW}, \eta=98 \%$ )

theoretical delay time calculated from the equations (1-3) and (9). The conversion efficiency was found to be around $98 \%$ at this operating condition.

Because of the resonant nature of the auxiliary current, the auxiliary switch turns on at zero current (ZCS) (Fig. 7(b) and 7(c)). This current becomes zero well before the auxiliary switch turn off transient (Fig. 7(b) and 7(c)). However, during the turn off transient, the MOSFET output capacitor charging current created a small current transient in the auxiliary branch (Fig. 6), which was only limited by the auxiliary inductance, $\mathrm{L}_{1}$ and the auxiliary circuit parasitic inductances. This current transient generated turn off losses in the auxiliary switch.

\section{Comparison with the Hard Switched Converter}

To evaluate the advantages of the converter the prototype was also run in the hard switched mode by disabling the auxiliary switches. One of the main switch's turn on and the turn off transients is shown in Fig. 8. From the turn on and the turn off transients the turn on energy and turn off energy is 


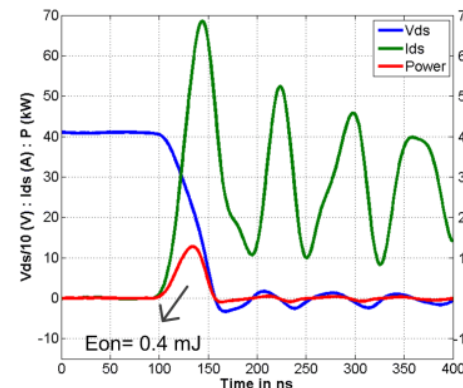

(a)

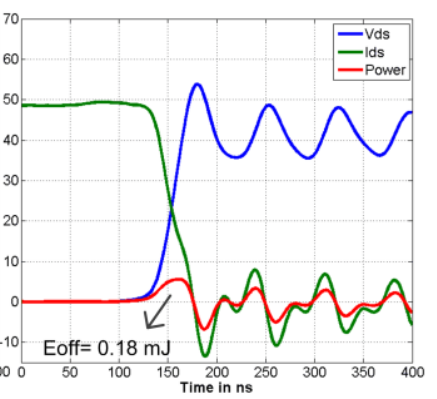

(b)
Fig. 8. Hard switched results: (a) Turn on transient and (b) Turn off transient

calculated to be $0.4 \mathrm{~mJ}$ and $0.18 \mathrm{~mJ}$, respectively. Therefore, for the $112 \mathrm{kHz}$ operation turn on and turn off power losses are in total $90 \mathrm{~W}$ and $40 \mathrm{~W}$, respectively. The reduction in switching losses in the soft switching converter is estimated to be $0.4 \mathrm{~mJ}$ per device due to the elimination of the turn on losses plus $1 / 2 \mathrm{C}_{\text {oss }} \mathrm{V}_{\text {out }}{ }^{2}=0.08 \mathrm{~mJ}$ due to the recovery of the energy stored in the device output capacitance at turn off, giving an overall reduction of switching related power loss of $108 \mathrm{~W}$.

Another improvement in the soft switching topology is the reduction of $d v / d t$ at the turn on transient. This is likely to reduce the EMC and parasitic ringing associated with the rapid switching of SiC MOSFETs. From Fig 7(b) and 7(c), the turn on $d v / d t$ is $3.3 \mathrm{kV} / \mu \mathrm{s}$ at the fastest part of the switching transient. In hard switching, this $d v / d t$ is found to be doubled to $6.6 \mathrm{kV} / \mu \mathrm{s}$ (Fig. $8(\mathrm{a})$ ).

\section{Loss breakdown}

To analyze further the effectiveness of the proposed topology a loss breakdown was undertaken. Table I shows the component losses at the rated condition $(174 \mathrm{~V}$ to $400 \mathrm{~V}, 112$ $\mathrm{kHz}$ and $12.6 \mathrm{~kW}$ ) based on the experimental results. Datasheet parameters such as MOSFET on resistances $\left(\mathrm{R}_{\mathrm{ds} \_ \text {on }}\right)$, gate charge $\left(\mathrm{Q}_{\mathrm{g}}\right)$, MOSFET anti-parallel diode on-state voltages $\left(\mathrm{V}_{\mathrm{sd}}\right)$, Schottky diode on-state voltages $\left(\mathrm{V}_{\mathrm{f}}\right)$, and magnetic core losses were used to formulate the loss breakdown [17-20].

MOSFET and diode losses were calculated based on the experimental wave-shapes. Magnetic component copper losses were measured using an impedance analyzer. It is clear from the table that the auxiliary circuit is responsible for $38.5 \mathrm{~W}$ loss which is around $16 \%$ of the total loss. However, as $108 \mathrm{~W}$ switching loss is eliminated compared to the hard switched operation, this soft switching topology still provides an efficiency advantage (around $0.5 \%$ ) over the hard switching operation.

The calculated efficiency at the rated power is $98.1 \%$, and in the experimental measurements, an efficiency of $98 \%$ was obtained based on input-output power measurements. At lower output powers, the measured efficiencies were all above $97 \%$.
TABLE I. LOSS BREAKDOWN OF THE PROTOTYPE CONVERTER (174 V TO $400 \mathrm{~V}, 112 \mathrm{KHZ}$ AND $12.6 \mathrm{KW}$ OPERATION)

\begin{tabular}{|c|c|c|}
\hline Loss factors & $\begin{array}{c}\text { Related } \\
\text { parameter } \\
\text { values }\end{array}$ & $\begin{array}{l}\text { Calculated loss } \\
\text { based on the } \\
\text { experiments } \\
(\mathrm{W})\end{array}$ \\
\hline \multicolumn{3}{|c|}{ Main circuit } \\
\hline $\mathrm{Q}_{1}$ and $\mathrm{Q}_{2}$ on state & $\mathrm{R}_{\mathrm{ds} \_ \text {on }}=14 \mathrm{~m} \Omega$ & 23.6 \\
\hline $\mathrm{Q}_{1}$ and $\mathrm{Q}_{2}$ switching & $F_{\mathrm{sw}}=112 \mathrm{kHz}$ & 22.4 \\
\hline $\mathrm{Q}_{3}$ and $\mathrm{Q}_{4}$ on state & $\mathrm{V}_{\mathrm{sd}}=1.35 \mathrm{~V}$ & 66.2 \\
\hline $\mathrm{L}_{2}$ copper & $\mathrm{R}_{\mathrm{L} 2}=1.8 \mathrm{~m} \Omega$ & 9.4 \\
\hline $\mathrm{L}_{2}$ core & & 10 \\
\hline IPT copper & $\mathrm{R}_{\mathrm{IPT}}=17 \mathrm{~m} \Omega$ & 22 \\
\hline IPT core & & 18 \\
\hline $\mathrm{Q}_{1}$ and $\mathrm{Q}_{2}$ gate drive & $\mathrm{Q}_{\mathrm{g}}=490 \mathrm{nC}$ & 2.7 \\
\hline \multicolumn{2}{|c|}{ Cooling fan loss $(W)$} & 23 \\
\hline \multicolumn{2}{|c|}{ Total main circuit loss $(W)$} & 197 \\
\hline \multicolumn{3}{|c|}{ Auxiliary circuit } \\
\hline $\mathrm{Q} 1_{\mathrm{A}}$ and $\mathrm{Q} 2_{\mathrm{A}}$ on state & $\mathrm{R}_{\mathrm{ds} \_ \text {on }}=90 \mathrm{~m} \Omega$ & 8.8 \\
\hline $\mathrm{Q} 1_{\mathrm{A}}$ and $\mathrm{Q} 2_{\mathrm{A}}$ switching & $\mathrm{F}_{\mathrm{sw}}=112 \mathrm{kHz}$ & 2 \\
\hline $\mathrm{Q} 1_{\mathrm{A}}$ and $\mathrm{Q} 2_{\mathrm{A}}$ gate drive & $\mathrm{Q}_{\mathrm{g}}=49.2 \mathrm{nC}$ & 0.2 \\
\hline $\mathrm{D}_{\mathrm{AUX} 1}$ and $\mathrm{D}_{\mathrm{AUX} 2}$ on state & $\mathrm{V}_{\mathrm{f}}=1.3 \mathrm{~V}$ & 18.2 \\
\hline $\mathrm{L}_{1}$ copper & $\mathrm{R}_{\mathrm{L} 1}=1.8 \mathrm{~m} \Omega$ & 8.3 \\
\hline $\mathrm{L}_{1}$ core & & 1 \\
\hline \multicolumn{2}{|c|}{ Total auxiliary circuit loss $(W)$} & 38.5 \\
\hline \multicolumn{2}{|c|}{ Total loss $(W)$} & 236 \\
\hline \multicolumn{2}{|c|}{ Calculated efficiency } & $98.1 \%$ \\
\hline
\end{tabular}

\section{CONCLUSION}

A converter topology has been presented which combines the soft switching operation of the SAZZ converter with the increased inductor frequency of the dual interleaved converter. Analytical waveforms and relevant equations have been presented along with the results of a $12.5 \mathrm{~kW}$ prototype operating in boost mode from $174 \mathrm{~V}$ to $400 \mathrm{~V}$.

The results of hard and soft switching tests show that the additional auxiliary components contribute an extra loss of $38.5 \mathrm{~W}$ at the $12.6 \mathrm{~kW}$ test point, however the switching losses are reduced from $130 \mathrm{~W}$ to $22.4 \mathrm{~W}$. This represents a reduction in the overall converter losses from $293.5 \mathrm{~W}$ to 236 $\mathrm{W}$. The efficiency of the prototype at $12.6 \mathrm{~kW}$ was measured to be approximately $98 \%$.

The major advantage of the topology is the significant reduction in $d v / d t$ at the turn on transient of about $50 \%$, without compromising the efficiency of the converter. The switching losses and $d v / d t$ at turn off of the main devices could be further reduced by the use of additional snubber capacitors, and the potential exists to integrate the auxiliary and main inductors, thereby reducing the component count.

The results confirm the viability of soft switching techniques for $\mathrm{SiC}$ converters and suggest that there is significant potential for further increases in switching frequencies.

\section{ACKNOWLEDGMENT}

The authors thank Dr. Ian Hawkins for his help in the design of the gate drivers. 


\section{REFERENCES}

[1] M. Johnson. (2013, 21/05/14). EPSRC Centre for Power Electronics. Delivering strategic value to the UK. EPSRC Centre for Power Electronics opening. Available: http://www.nmi.org.uk/assets/files/ networks/iPower3/Presentations/9 EPSRC Centre ipower nov13.pdf

[2] G. Calderon-Lopez, A. J. Forsyth, D. L. Gordon, and J. R. McIntosh, "Evaluation of SiC BJTs for High-Power DC-DC Converters," IEEE Transactions on Power Electronics, vol. 29, pp. 2474-2481, 2014.

[3] G. Calderon-Lopez and A. J. Forsyth, "High power density DC-DC converter with $\mathrm{SiC}$ MOSFETs for electric vehicles," 7th IET International Conference on Power Electronics, Machines and Drives (PEMD 2014) Manchester, UK 2014.

[4] E. Sanchis-Kilders, A. Ferreres, E. Maset, J. D. Ejea, V. Esteve, J Jordan, R. Garcia, and A. Garrigos, "High Power Passive Soft Switched Interleaved Boost Converters," 35th Annual IEEE Power Electronics Specialists Conference, Aachen, Germany, 2004, pp. 426-432.

[5] J. H. Zhang, J. S. Lai, R. Y. Kim, and W. S. Yu, "High-power density design of a soft-switching high-power bidirectional dc-dc converter," IEEE Transactions on Power Electronics, vol. 22, pp. 1145-1153, Jul 2007.

[6] G. Calderon-Lopez and A. J. Forsyth, "High-Power Dual-Interleaved ZVS Boost Converter with Interphase Transformer for Electric Vehicles," Applied Power Electronics Conference and Exposition, APEC 2009, Washington DC, USA, 2009, pp. 1-6.

[7] W. Li and X. He, "ZVT Interleaved boost converters for high-efficiency, high step-up DC-DC conversion," Electric Power Applications, IET Proceedings-, vol. 1, pp. 284-290, March 2007.

[8] Y. Tsuruta and A. Kawamura, "Zero voltage switched chopper with SiCMOSFETs," Energy Conversion Congress and Exposition (ECCE), 2013.

[9] M. Pavlovsky, Y. Tsuruta, and A. Kawamura, "Pursuing high powerdensity and high efficiency in DC-DC converters for automotive application," IEEE Power Electronics Specialists Conference (PESC), 2008.

[10] Y. Tsuruta, M. Pavlovsky, G. Guidi, and A. Kawamura, "Four quadrant SAZZ-1 chopper for EV and HEV power train," IEEE 8th International Conference on Power Electronics and ECCE Asia (ICPE \& ECCE), 2011.
[11] Y. Tsuruta, M. Pavlovsky, and A. Kawamura, "Conditions Limiting the Formation of the ZVZCT Switching in SAZZ Converter," Industry Applications Conference, 2007. 42nd IAS Annual Meeting. Conference Record of the 2007 IEEE, 2007.

[12] N. Oswald, P. Anthony, N. McNeill, and B. H. Stark, "An Experimental Investigation of the Tradeoff between Switching Losses and EMI Generation With Hard-Switched All-Si, Si-SiC, and All-SiC Device Combinations," IEEE Transactions on Power Electronics, vol. 29, pp. 2393-2407, 2014.

[13] F. J. Bryan and A. J. Forsyth, "A power dense DC-DC converter for a small electric vehicle," in Power Electronics, Machines and Drives (PEMD 2012), 6th IET International Conference on, 2012, pp. 1-6.

[14] A. J. Forsyth and G. Calderon-Lopez, "Sampled-Data Analysis of the Dual-Interleaved Boost Converter With Interphase Transformer," IEEE Transactions on Power Electronics, vol. 27, pp. 1338-1346, 2012.

[15] M. Hirakawa, Y. Watanabe, M. Nagano, K. Andoh, S. Nakatomi, S. Hashino, and T. Shimizu, "High power DC/DC converter using extreme close-coupled inductors aimed for electric vehicles," in Power Electronics Conference (IPEC), 2010 International, 2010, pp. 2941 2948.

[16] M. Pavlovsky, G. Guidi, and A. Kawamura, "Buck/Boost DC-DC Converter Topology With Soft Switching in the Whole Operating Region," IEEE Transactions on Power Electronics, vol. 29, pp. 851-862, Feb. 2014.

[17] CREE Inc., "CAS100H12AM1 1200V, 100A Silicon Carbide HalfBridge Module. Product datasheet Rev. C," CREE Inc., 2013.

[18] CREE Inc. "C2M0080120D Silicon Carbide Power MOSFET C2M MOSFET Technology. Product datasheet. Rev. B," CREE, 2014.

[19] CREE Inc. "C4D40120D Silicon Carbide Schottky Diode, Product datasheet. Rev. E," CREE, 2014.

[20] Ferroxcube, "Ferroxcube Catalogue, Ferrite cores," in Soft ferrites and accesories. Ferroxcube, 2008. 